\title{
The study of immunity in children with chronic nasopharyngitis
}

\begin{abstract}
This article deals with the problem of frequent exacerbation of nasopharyngitis in children. The paper studied the immune status in children with chronic nasopharyngitis. It is revealed that children with chronic nasopharyngitis had decreased content of IgA decrease, the decrease in CD25+ lymphocytes, a decrease in CD4+. All examined children received therapy by likopid $1 \mathrm{mg}$ per day for 10 days, a second course was performed after 1 month. It is revealed that therapy by likopid patients with chronic nasopharyngitis normalizes reduced immune status indices: increase in the content of CD3+ and CD25+, the increase in the concentration of $\operatorname{IgA}$.
\end{abstract}

Keywords: chronic nasopharyngitis, children, immunity, immunocorrector
Volume 7 Issue 2 - 2018

\author{
Ivanova Olga Nikolaevna \\ Department of Pediatrics and pediatric surgery, North-Eastern \\ Federal University named after M.K. \\ Ammosov, Russia

\begin{abstract}
Correspondence: Ivanova Olga Nikolaevna, Doctor of medical Sciences, Professor of Department of Pediatrics and pediatric surgery, MI NEFU, North-Eastern Federal University named after M.K.Ammosov, Yakutsk, Russia, Tel 89142906/25, Email olgadoctor@list.ru
\end{abstract}

Received: March 14, 2018| Published: April 09, 2018

\section{Introduction}

Nasopharyngitis is an inflammatory disease of the mucous membranes and pharyngitis. It is up to eighty percent of cases of acute respiratory viral infection accompanied by nasopharyngitis., Isolated hypertrophic and atrophic forms of chronic nasopharyngitis. Pathomorphological changes in hypertrophic form is characterized by thickening and edema of mucous and submucous layers of the nasopharynx, so the clinical picture observed increased secretion from the nose light transparent liquid, the feeling of rawness and throat irritation, increased lacrimation, and tickling in the nose. The patient coughs constantly, expectorated and sneezing especially in the morning. Atrophic nasopharyngitis is characterized by thinning of the mucosa, since the affected layer is replaced by connective tissue fibers. Accordingly, the clinic is of a different nature and is manifested by dryness in the throat, difficulty swallowing and bad breath. The child of early age the frequency of appearance of virus infections with nasopharyngitis is caused by immune system dysfunction, increased allergic reactions, the presence of chronic adenoiditis. ${ }^{1-4}$ The purpose of the study to characteristics of immunity in children with chronic nasopharyngitis and the effect of drug therapy Likopid.

\section{Materials and methods}

The study surveyed a group of children $(n=30)$ aged 3 to 5 years with chronic nasopharyngitis: the common rhinitis, sore throat, nasal discharge. Was also surveyed a group of healthy children $(n=20)$, and compare groups of children matched for age. The children underwent examination of immune status (CD3+,CD4+, CD8+, CD16+, CD22+, $\operatorname{Ig} \mathrm{A}, \mathrm{IgG}, \operatorname{IgM}, \mathrm{IgE}$ ) on the basis of National center of medicine (I). Comparison of mean values was assessed single-factor dispersion analysis using T-test, Student for the evaluation of the equality F-Fisher criterion. The relationship between parameters was assessed using the coefficients of the linear and rank correlation.

\section{Results}

The results of the study all children with chronic nasopharyngitis was marked by frequent viral respiratory infections, nasal discharge, excessive sweating, fatigue, adenoiditis. There were examined 30 children. In the group of all children surveyed have observed a reduced level of IgA (Table 1). Also noted a decrease in the content of CD25+ cells, activated T cells, T helper (CD4+). In the treatment of chronic nasopharyngitis were used in the course of immunomodulator Likopid in the dose of $1 \mathrm{mg}$ ( 1 tablet ) 1 times a day 10 days, a second course was conducted in a month. At the end of the second course was conducted immunological studies all treated children (Table 2). Therapy by drug Likopid led to the normalization of some parameters of cellular and humoral immunity: the increase in the content of CD3+ and $\mathrm{CD} 25+$, the increase in the concentration of $\operatorname{IgA}$.

Table I Indicators of immune status in children of Sakha (Yakutia) in children with chronic nasopharyngitis and healthy children

\begin{tabular}{|c|c|c|}
\hline Indicators & $\begin{array}{l}\text { Indicators of children with } \\
\text { chronic nasopharyngitis } \\
(n=30) M \pm m\end{array}$ & $\begin{array}{l}\text { Healthy children(n } \\
=20) \mathrm{M} \pm \mathrm{m}\end{array}$ \\
\hline $\mathrm{CD} 3+$ & $26,4 \pm 1,0$ & $27,2 \pm 1,04$ \\
\hline CD4+ & $10,1 \pm 0,2^{*}$ & $21,3 \pm 0,6$ \\
\hline CD8+ & $11,2 \pm 0,5$ & $|2| \pm 2.5$, \\
\hline CDI6+ & $12,4 \pm I, 4$ & $|I, 0 \pm I, 0|$ \\
\hline IRI & $0,8 \pm 0,5$ & $\mathrm{I}, 08 \pm 0,02$ \\
\hline $\lg A$ & $1,6 \pm 0,1 *$ & $2,9 \pm 0,6$ \\
\hline $\lg G$ & $|8| \pm 0,2$, & $17,1 \pm 0,09$ \\
\hline $\lg M$ & $2,6 \pm 0,02$ & $2,2 \pm 0,09$ \\
\hline CD25+ & $12,2 \pm 1,2 *$ & $24,6 \pm 0,7$ \\
\hline CIK & $75, I \pm I, 5<0,05$ & $70 \pm 0,07$ \\
\hline
\end{tabular}

$*_{p}<0.05$ between norms and obtained values in each group. 
Table 2 Indicators of immune status in children of Sakha (Yakutia) in children with chronic nasopharyngitis before and after therapy likopid

\begin{tabular}{|c|c|c|}
\hline Indicators & $\begin{array}{l}\text { Indicators of children with } \\
\text { chronic nasopharyngitis before } \\
\text { likopid }(n=30) \mathrm{M \pm m}\end{array}$ & $\begin{array}{l}\text { Indicators of children with } \\
\text { chronic nasopharyngitis } \\
\text { after likopid }(n=30) M \pm m\end{array}$ \\
\hline CD3+ & $26,4 \pm 1,0$ & $28,9 \pm 0,08$ \\
\hline CD4+ & $|0| \pm 0,2$, & $25,3 \pm 0,07 *$ \\
\hline CD8+ & $1 \mathrm{I}, 2 \pm 0,5$ & $21,8 \pm 2.5$ \\
\hline CDI6+ & $\mid 2,4 \pm I, 4$ & $12,4 \pm 0,09$ \\
\hline IRI & $0,8 \pm 0,5$ & $1,2 \pm 0,02$ \\
\hline $\lg A$ & $I, 6 \pm 0, I$ & $3,0 \pm 0,6 *$ \\
\hline $\lg G$ & $|8| \pm 0,2$, & $20, I \pm 0,05$ \\
\hline $\lg M$ & $2,6 \pm 0,02$ & $2,5 \pm 0,8$ \\
\hline CD25+ & $12,2 \pm 1,2$ & $22,4 \pm 0,4^{*}$ \\
\hline CIK & $75,1 \pm 1,5<0,05$ & $45 \pm 0,07^{*}$ \\
\hline
\end{tabular}

$*_{p}<0.05$ between norms and obtained values in each group.

\section{Discussion}

Nasopharyngitis treatment includes antibiotic therapy, electroprocedures and warming of the nasopharynx. Since the content of IgA, CD25+ lymphocytes, CD4+ was reduced in children with chronic nasopharyngitis, all examined children were treated with lycopene $1 \mathrm{mg}$ per day for 10 days, the repeated course was held in 1 month. This treatment improved the condition of the patient and was the prevention of possible exacerbations.

\section{Conclusion}

a. In children with chronic nasopharyngitis revealed the immune dysfunction or failure, affecting cellular and humoral immunity (IgA decrease, the decrease in CD25+ lymphocytes, reduced CD4+).

b. Therapy by likopid patients with chronic nasopharyngitis normalizes reduced immune status indices: increase in the content of $\mathrm{CD} 3+$ and $\mathrm{CD} 25+$, the increase in the concentration of $\operatorname{IgA}$.

\section{Acknowledgment}

None.

\section{Conflict of interest}

None.

\section{References}

1. Ratnikova LI. New approach to treatment of acute respiratory viral infections and influenza. Poliklinika. 2009;2:70-72.

2. Klyuchnikov SO. Acute respiratory infections in children. Russian Bulletin of Perinatology and Pediatrics. 2008;3:1-36.

3. Oxford JS, Lambkin R, Gibb I, et al. A throat lozenge containing amyl meta cresol and dichlorobenzyl alcohol has a direct virucidal effect on respiratory syncytial virus, influenza A and SARS-CoV. Antivir Chem Chemother. 2005;16(2):129-34.

4. Coulthard CE. The Disinfectant and Antiseptic Properties of Amyl-metacresol. Br J Exp Pathol. 1931;12:331-336. 